\title{
Undetected acute aortic dissection in a patient referred for primary coronary angioplasty: a successful treatment of perioperative bleeding after abciximab administration
}

\author{
A Arrivi, ${ }^{1}$ G Tanzilli, ${ }^{1}$ L Tritapepe, ${ }^{2}$ G Mazzesi, ${ }^{3}$ E Mangieri' \\ ${ }^{1}$ Heart and Great Vessels "A. Reale" Second Division of Cardiology, Policlinico Umberto I, Sapienza University, Rome, Italy \\ ${ }^{2}$ Heart and Great Vessels "A. Reale” Departmental Unit of Anesthesia and Intensive Care in Cardiac Surgery, Policlinico Umberto I, Sapienza University, Rome, Italy \\ ${ }^{3}$ Heart and Great Vessels "A. Reale" Departmental Unit of Cardiac Surgery, Policlinico Umberto I, Sapienza University, Rome, Italy
}

Correspondence to A Arrivi, alessio.arrivi@libero.it

\section{Summary}

The authors describe a case of an acute aortic dissection in a Japanese woman with long-lasting hypertension, who was referred to our cath lab for primary percutaneous coronary intervention because of an ECG feature of acute inferior myocardial infarction and systemic hypotension. A successful treatment of perioperative bleeding followed a missed diagnosis in the early stages and abciximab administration.

\section{BACKGROUND}

Acute myocardial infarction (AMI) due to acute aortic dissection is not frequent. ${ }^{12}$ An early diagnosis is essential to improve the patients' prognosis. ${ }^{3}$ We report a case of an Japanese woman with an acute inferior myocardial infarction secondary to an acute aortic dissection, which was ignored in the early stages despite investigation in hospital. A multifactorial treatment based on platelet transfusion and rFVIIa administration reversed the bleeding effect of the early administration of abciximab.

\section{CASE PRESENTATION}

A 53-year-old Japanese woman with chronic hypertension, who was on holiday in our town, presented to the emergency room of our hospital complaining of the sudden onset of severe chest pain radiating to her back.
She had a blood pressure of 90/70 $\mathrm{mm} \mathrm{Hg}$ and heart rate of $70 \mathrm{bpm}$. The ECG showed a marked ST-segment elevation in leads II, III and aVF and a reciprocal ST-segment depression in V2 through V4 precordial leads suggesting an inferior wall AMI (figure 1). Because of the fast decline of the haemodynamic parameters neither a chest x-ray film nor transthoracic echocardiogram was performed. In the emergency room, the patient received oral aspirin $250 \mathrm{mg}$, ranitidine $50 \mathrm{mg}$ intravenously, heparin $4.000 \mathrm{UI}$ and an intravenous bolus of abciximab (Reopro, Eli Lilly, Indianapolis, IN, USA) $0.25 \mathrm{mg} / \mathrm{kg}$ body weight, and she was immediately transferred to our cath lab for a primary percutaneous coronary intervention (PCI). The angiogram, carried out through the right femoral artery, showed a slow anterograde filling of the left coronary artery, without any atherosclerotic narrowing, and a significant stenosis on the

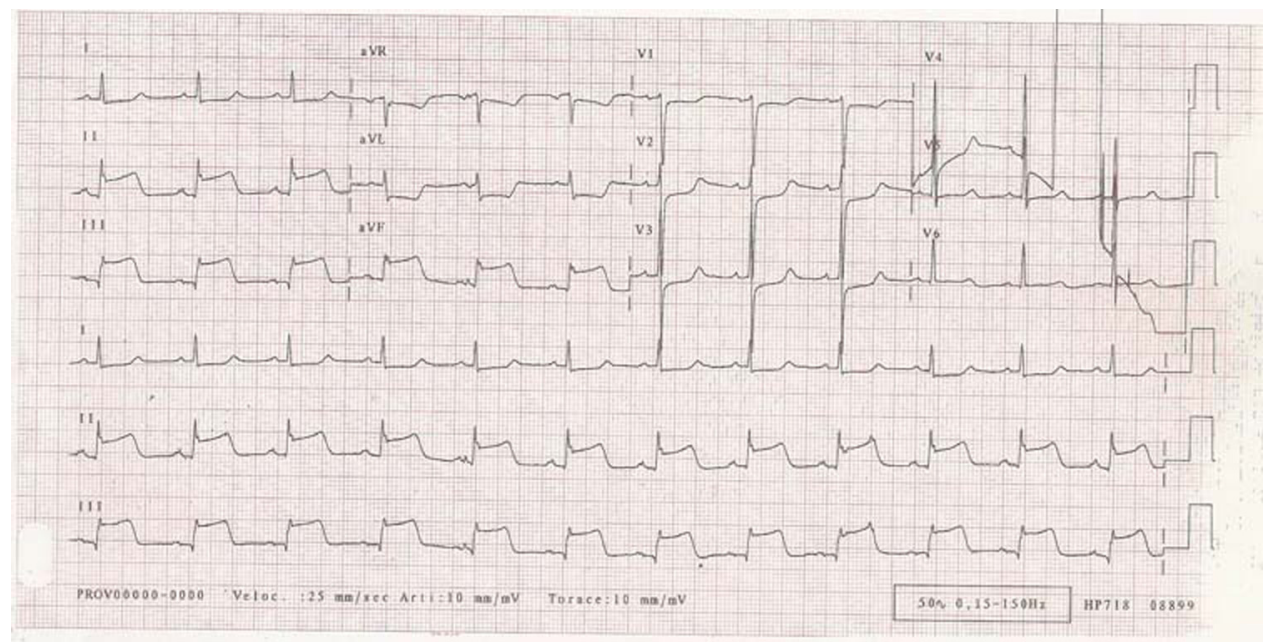

Figure 1 ECG showing a marked ST-segment elevation in leads II, III and aVF and a reciprocal ST-segment depression in V2 through V4 precordial leads. 


\section{BMJ Case Reports}

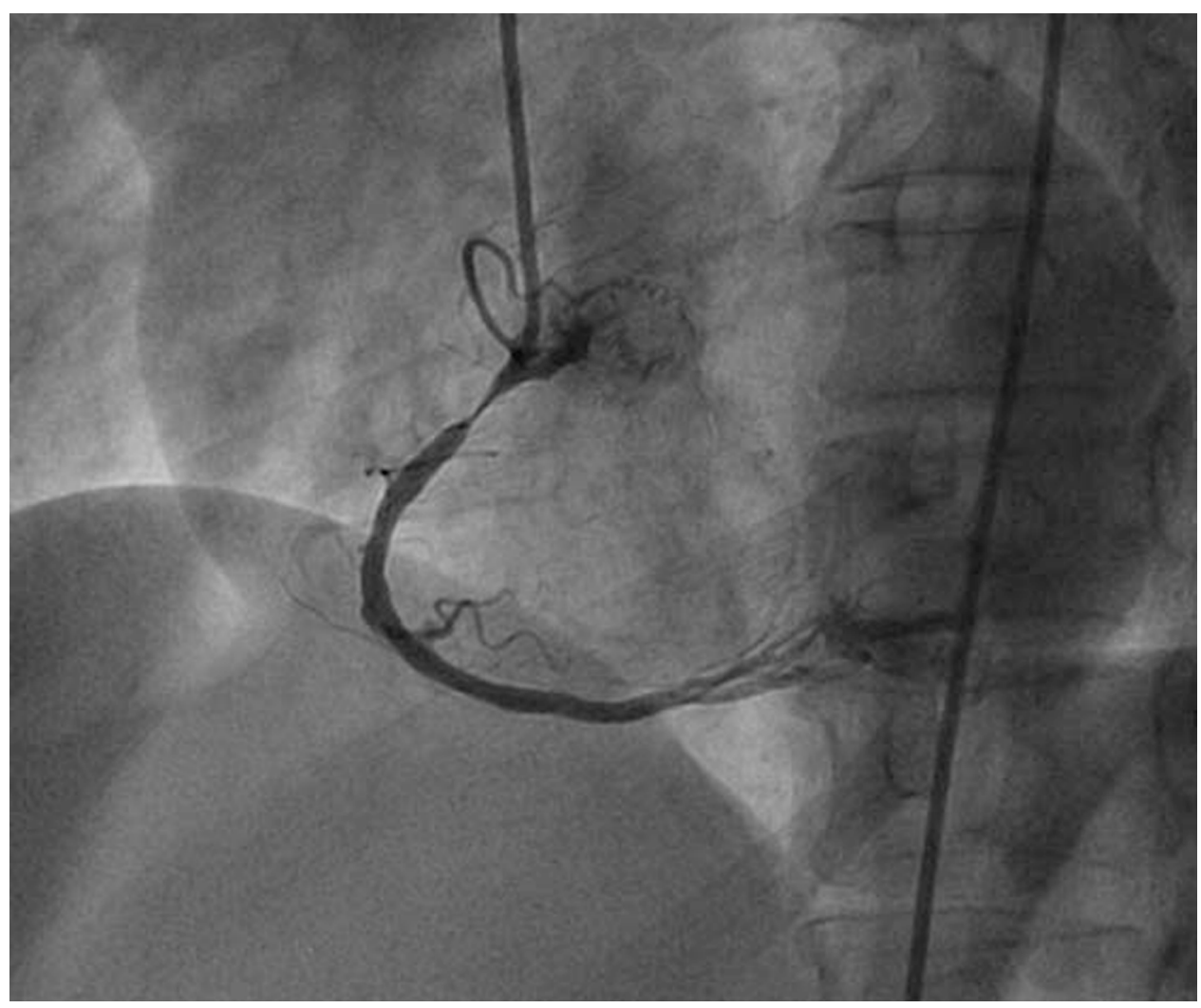

Figure 2 Injection in the right coronary artery showing a critical obstruction in the first tract of the vessel.

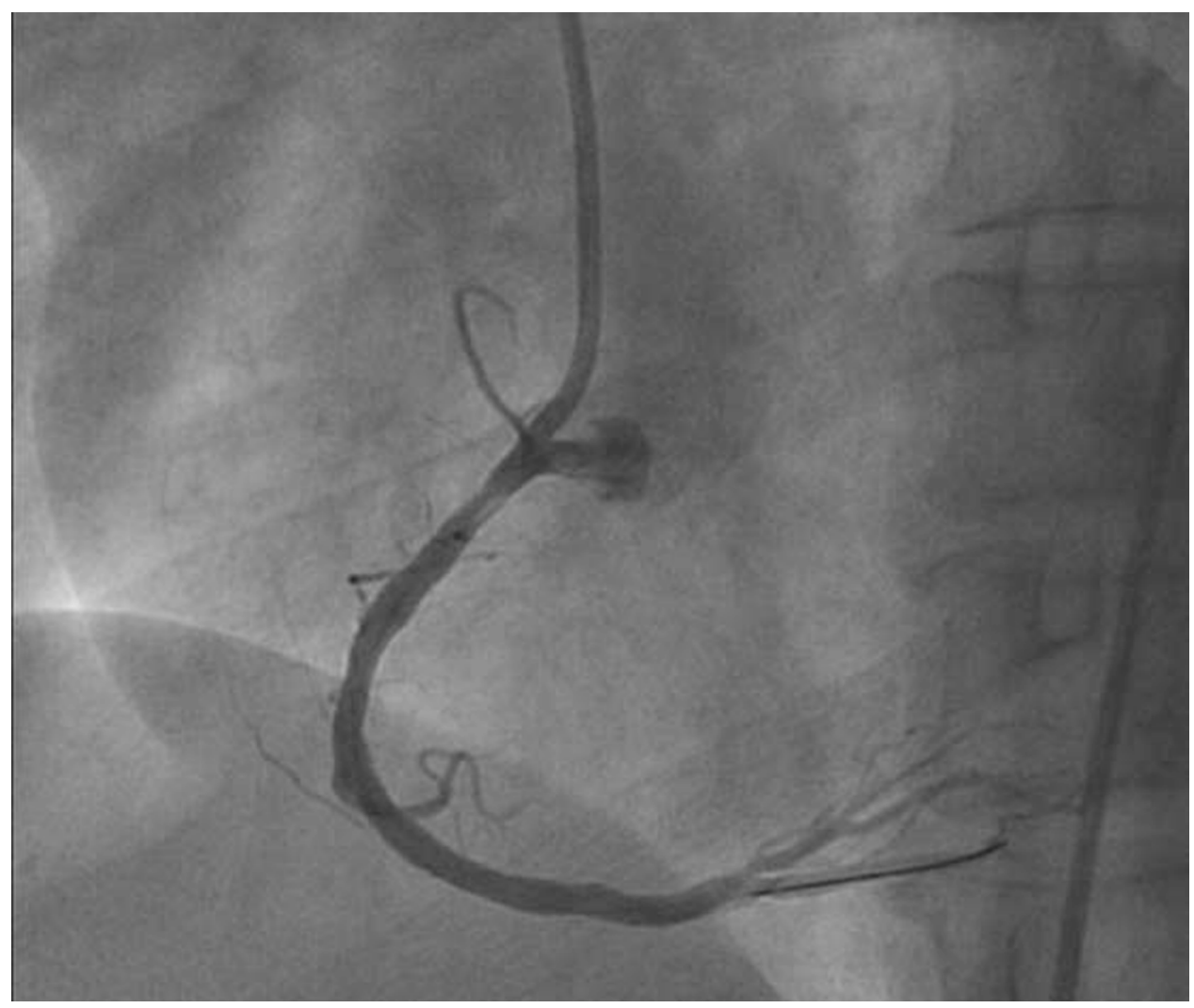

Figure 3 Attempt of percutaneous coronary intervention: the obstruction disappears at the simple crossing of the balloon without inflation. 


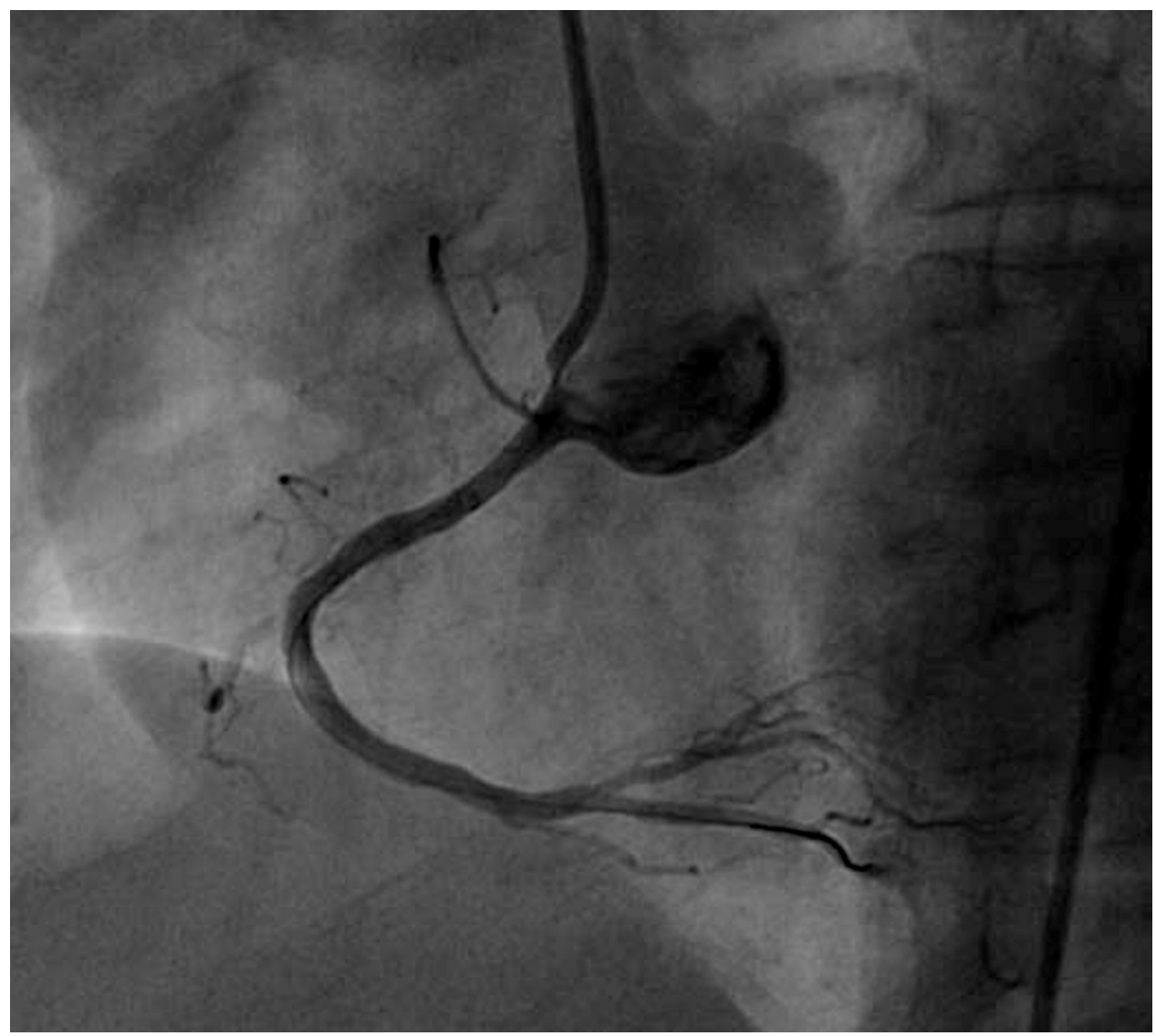

Figure 4 Injection outside the right coronary ostium showing the passage of contrast into the left ventricle and a clear dilatation of the aortic root.

first tract of the right coronary artery (figure 2). An intracoronary dose of nitroglycerine $(100 \mu \mathrm{g})$ was injected to exclude a catheter-induced spasm. Thus, the operator decided to perform a primary PCI by crossing the lesion with a guide-wire.

Surprisingly, the stenosis disappeared when the ballooncatheter (Sapphire, OrbusNeich, Hong Kong, China) was placed at the site of the lesion without inflation (figure 3). The operator then pulled back the catheter just outside the right coronary ostium and performed an injection, which demonstrated the passage of contrast into the left ventricle and a clear dilatation of the aortic root (figure 4). The following aortogram showed an aortic dissection (Stanford type A) with secondary compression and torsion of the right coronary artery and epiaortic vessels and severe aortic regurgitation (figure 5). The patient was treated with intravenous infusion of plasma-expander and dopamine and she was brought to cardiac surgery for an emergency intervention. At the thoracic opening the heart appeared to be constricted by a massive pericardial blood shedding and the aortic wall was stuffed. The surgeon carried out the aortic root replacement with the implantation of a biological Freestyle (Medtronic Inc, Minneapolis, MN, USA) aortic prosthesis $n{ }^{\circ} 23$ (full root technique) and the interposition of an InterVascular (Montvale, New Jersey, USA) prosthetic tube $n{ }^{\circ} 22$. The patient received red blood cell ( $3 \mathrm{U}$ ) and fresh frozen plasma (5 U) transfusion at the end of cardiopulmonary bypass (CPB). Due to the relevant bleeding, 10 units of platelets were also given. Since bleeding was still uncontrolled, a dose of rFVIIa $70 \mathrm{mcg} / \mathrm{kg}$ was administered as an intravenous bolus. A second dose was administered after 1 $\mathrm{h}$ to reduce blood loss to $<150 \mathrm{ml} / \mathrm{h}$. Coagulation tests were monitored before and $1 \mathrm{~h}$ after the dose of rFVIIa. The postoperative course was regular and the CT demonstrated a good result of the intervention and the presence of a residual flap of dissection involving the descending aorta with involvement of the superior pole of the left kidney. Because of the good condition of the patient and the preservation of the renal function no further step was taken. Apart from a pericardial effusion in the eleventh postoperative day, which required drainage, the patient made an excellent recovery and was discharged 18 days after the operation.

\section{OUTCOME AND FOLLOW-UP}

The patient returned to her country and, to our knowledge, is free from events.

\section{DISCUSSION}

AMI is a relatively rare complication of acute aortic dissection with an incidence of $1-2 \% .{ }^{12}$ The right coronary artery is more often affected than the left. ${ }^{3}$ A correct and timely diagnosis is essential to save the patient. ${ }^{4}$ This case accounts for two methodological errors: the first one has been the lack of an accurate physical examination with regard to cardiac auscultation and peripheral pulse exploration. An aortic regurgitant murmur due to prolapse of the aortic valve is 


\section{BMJ Case Reports}

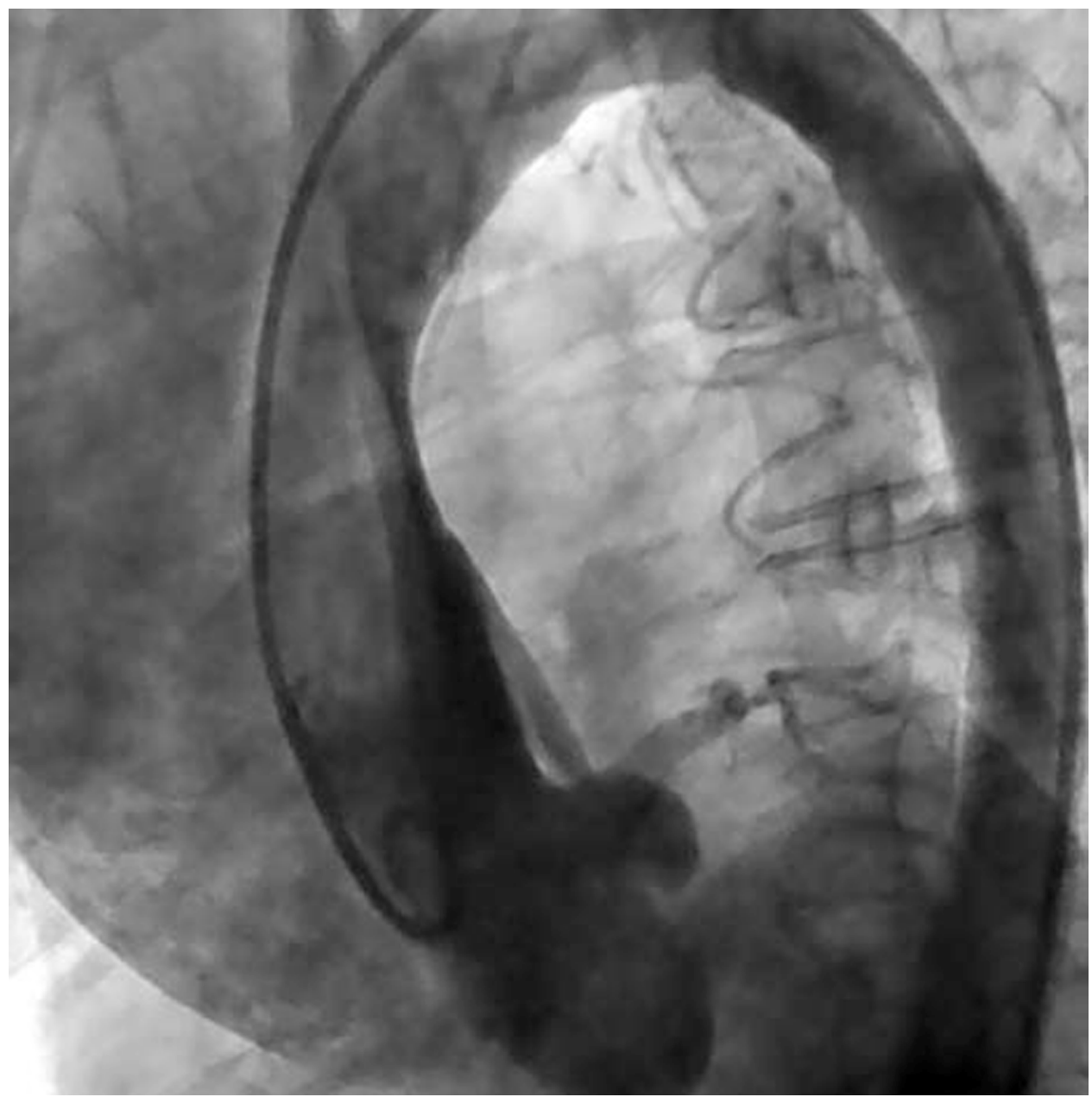

Figure 5 Aortogram showing acute aortic dissection with secondary compression of the right coronary artery and epiaortic vessels, and severe aortic regurgitation.

often present, and missing and varying pulses support the diagnosis. ${ }^{5}$ The second error may be considered to be the absence of an echocardiogram or chest $\mathrm{x}$-ray film in the early stages despite investigation in hospital. The presence of an intimal flap at the transthoracic echocardiogram with the evidence of aortic regurgitation, or an abnormal mediastinal widening at $\mathrm{x}$-ray film, would have been sufficient to make a correct diagnosis. Moreover, the administration of a loading dose of abciximab has largely inhibited the platelet aggregation. The haemostatic mechanism has been severely affected; thus, increasing blood loss and transfusion requirement. Potential strategies for managing patients who have been given abciximab and require emergency cardiac operation include delaying operation, administration of exogenous platelets and reduce heparin injection before CPB. ${ }^{6}$ Pharmacodynamic studies demonstrate gradual platelet functional recovery after discontinuation of abciximab infusion such that bleeding time and platelet aggregation return to near normal levels $12 \mathrm{~h}$ after dosing. 'Thus, delay of the operation until clearance of the IIb/IIIa inhibitor is a reasonable strategy. However, this was not possible in our patient so the strategy was based on a multifactorial therapeutic approach to bleeding. Within the cardiac surgery population, patients undergoing operations for acute type A aortic dissection have a very high risk of postoperative bleeding. The haemostatic defect associated with $\mathrm{CPB}$ surgery is often multifactorial. A coagulopathy as a direct consequence of the surgery itself, the $\mathrm{CPB}$ procedure with the associated moderate hypothermia and preoperative antithrombotic treatment are all implicated. In addition to these factors, a coagulopathy may be associated with the underlying aortic pathology and an enhancement of the haemostatic defect may occur in deep hypothermic circulatory arrest (DHCA) as a consequence of the lower temperatures used and blood stasis. The administration of rFVIIa to patients who develop massive refractory bleeding after acute aortic dissection surgery with DHCA may be safe and result in a significant reduction of blood loss and transfusion requirement. $^{8}$ 


\section{Learning points}

- Physicians should pay more attention to secondary ischaemic heart disease and not ignore the role of 'first line investigations,' such as physical examination, transthoracic echocardiogram and chest $\mathrm{x}$-ray.

- In case of doubt, an injection just outside the coronary ostium, before any invasive interventions, helps the operator to clarify the correct approach.

- A treatment based on platelet transfusion and rFVIla administration can be useful to limit the perioperative bleeding in patients with undetected acute aortic dissection inappropriately treated with abciximab.

Competing interests None.

Patient consent Obtained.

\section{REFERENCES}

1. Ohtani N, Kiyokawa K, Asada H, et al. Stanford type A acute dissection developing acute myocardial infarction. Jpn J Thorac Cardiovasc Surg 2000;48:69-72
2. Ikari Y, Hara K, Tamura T, et al. Intracoronary stenting of a coronary occlusion resulting from an aortic dissection. Cathet Cardiovasc Diagn 1995; $\mathbf{3 6}: 160-3$.

3. Spittell PC, Spittell JA Jr, Joyce JW, et al. Clinical features and differential diagnosis of aortic dissection: experience with 236 cases (1980 through 1990). Mayo Clin Proc 1993:68:642-51.

4. Tarver K, Kindler H, Lythall D. Extensive aortic dissection presenting as acute inferior myocardial infarction. Heart 2007;93:1225.

5. Butler J, Davies AH, Westaby S. Streptokinase in acute aortic dissection. BMJ 1990;300:517-9.

6. Tronc F, Robin J, Hanss M, et al. Aortic hemi-arch replacement for acute type A aortic dissection in an Abciximab-treated patient. J Cardiovasc Surg (Torino) 2007;48:672-3.

7. The Epic Investigators. Use of a monoclonal antibody directed against the platelet glycoprotein Ilb/lla receptor in high risk coronary angioplasty. The EPIC Investigation. N Engl J Med 1994;330:956-61.

8. Tritapepe L, De Santis V, Vitale D, et al. Recombinant activated factor VII for refractory bleeding after acute aortic dissection surgery: a propensity score analysis. Crit Care Med 2007;35:1685-90.

\footnotetext{
This pdf has been created automatically from the final edited text and images.

Copyright 2010 BMJ Publishing Group. All rights reserved. For permission to reuse any of this content visit http://group.bmj.com/group/rights-licensing/permissions.

BMJ Case Report Fellows may re-use this article for personal use and teaching without any further permission.

Please cite this article as follows (you will need to access the article online to obtain the date of publication).

Arrivi A, Tanzilli G, Tritapepe L, Mazzesi G, Mangieri E. Undetected acute aortic dissection in a patient referred for primary coronary angioplasty: a successful treatment of perioperative bleeding after abciximab administration. BMJ Case Reports 2010;10.1136/bcr.10.2010.3382, date of publication

Become a Fellow of BMJ Case Reports today and you can:

- Submit as many cases as you like

- Enjoy fast sympathetic peer review and rapid publication of accepted articles

- Access all the published articles

- Re-use any of the published material for personal use and teaching without further permission

For information on Institutional Fellowships contact consortiasales@bmjgroup.com

Visit casereports.bmj.com for more articles like this and to become a Fellow
} 